\title{
A DIDÁTICA A SERVIÇO DA INCLUSÃO DE ESTUDANTES COM DEFICIÊNCIA NA ESCOLA COMUM
}

Susana Couto Pimentel ${ }^{\mathrm{i}}$

\begin{abstract}
Resumo: Este artigo objetiva abordar como a didática pode estar a serviço da inclusão de estudantes com deficiência inseridos na escola comum numa educação emancipadora. Esta discussão foi desenvolvida a partir de estudos realizados sobre o tema. A escola, como um espaço onde se encontram as diferenças, precisa ser um espaço de transformação social, no qual as práticas que são cotidianamente construídas podem contribuir para uma educação transformadora. Os resultados desta reflexão apontam o princípio da inclusão educacional requer compromisso com o desenvolvimento de uma didática inclusiva, que favoreça a criação de condições para que todos tenham na escola o direito de aprender e o acesso aos conhecimentos necessários para o exercício da cidadania e autonomia na sociedade.
\end{abstract}

Palavras-chave: Didática. Inclusão. Estudantes com deficiência.

\section{LA DIDÁTICA AL SERVICIO DE LA INCLUSIÓN DE ESTUDIANTES CON DISCAPACIDAD EN LA ESCUELA COMÚN}

Resumen: Este artículo objetiva abordar cómo la didáctica puede estar al servicio de la inclusión de estudiantes con discapacidad insertados en la escuela común en una educación emancipadora. Esta discusión fue desarrollada a partir de estudios realizados sobre el tema. La escuela, como un espacio donde se encuentran las diferencias, necesita ser un espacio de transformación social, en el cual las prácticas que son cotidianamente construidas pueden contribuir a una educación transformadora. Los resultados de esta reflexión apuntan al principio de la inclusión educacional requiere compromiso con el desarrollo de una didáctica inclusiva que favorezca la creación de condiciones para que todos tengan en la escuela el derecho de aprender y el acceso a los conocimientos necesarios para el ejercicio de la ciudadanía y autonomía en Sociedad.

Palabras clave: Didáctica. Inclusión. Estudiantes con discapacidad.

\section{Introdução}

Neste artigo a reflexão sobre a didática é proposta considerando não apenas a sua dimensão técnica, mas, sobretudo, a sua dimensão política. De acordo com o mestre Paulo Freire (1921-1997), reconhecido como patrono da educação brasileira através da Lei $\mathrm{n}^{\circ}$ 12.612/2012, educar é um ato político, pois é intrinsecamente comprometido com a formação do cidadão e a construção da sociedade. Portanto, não se pode falar sobre educação e ensino sem 
que seja definido a priori por cada escola que homem e que sociedade pretendem formar. Tal definição é assumida, consequentemente, pelos docentes, ainda que não no plano da consciência, em seu fazer pedagógico.

Defender o princípio da inclusão educacional de todas as pessoas, independente de sua condição física, sensorial ou cognitiva, é, portanto, assumir a educação como um ato político, pois na perspectiva inclusiva se pretende a construção de uma sociedade mais justa e fundamentada no princípio da equidade. Entende-se equidade como a disposição para se reconhecer, de modo imparcial, o direito de todas as pessoas ao que lhes é assegurado como cidadãos, garantindo-lhes a equiparação de oportunidades para o acesso a tais direitos. De acordo com Santos (2013, p. 33),

a igualdade equitativa de oportunidade vem ao encontro de dar a oportunidade independente dessas variantes, que são as diferenças postas. (...) igualdade equitativa exige que todos tenham chances equitativas de acesso ao que está sendo oferecido, não sendo privado por condições econômicas e sociais que o diferencia de outro.

Observe-se que o conceito de equidade pressupõe que todos tenham acesso ao que é oferecido, independente das diferenças reais. Em termos educacionais é possível se falar, portanto, de equidade como o reconhecimento e a criação de condições para que todos tenham na escola acesso ao direito de aprender, embora se reconheça que educação se dá não apenas no âmbito escolar.

Conforme estabelecido no Art. 205 da Constituição Federal de 1988, a educação é direito de todas as pessoas e dever do Estado e da família, sendo assegurada com a colaboração da sociedade, "visando ao pleno desenvolvimento da pessoa, seu preparo para o exercício da cidadania e sua qualificação para o trabalho" (BRASIL, 1988). Quando se defende educação como direito, abrange-se o direito de aprender, pois não é possível se falar em educação sem se reconhecer que a mesma propicia a reconstrução interna de saberes construídos com o outro. Portanto, assume-se neste trabalho o conceito vigotskiano de aprendizagem que envolve a internalização dos saberes trabalhados a partir da mediação do outro.

Porém, para que tal aprendizagem se efetive requer considerarem-se as diferenças individuais. No âmbito escolar, isso significa o reconhecimento do que é próprio de cada aluno que internaliza o construído socialmente de modo singular, único, peculiar, isto é, de modo individualizado. (VIGOTSKI, 2001). Esse modo particular de aprender requer, necessariamente, procedimentos didáticos também particulares. Isso não quer dizer aulas individualizadas para cada aluno, mas a consciência de que as formas de ensinar precisam estar intrinsecamente relacionadas aos modos de aprender. 
Conforme visto, de acordo com a Constituição brasileira, a educação é direito de todos (BRASIL, 1988), porém, assegurar esse direito constitucionalmente é apenas o começo. É necessário que, a partir do reconhecimento desse direito, os atores da educação construam possibilidades para que todos tenham não apenas o acesso à escola, mas que consigam permanecer nesta instituição tendo também acesso ao conhecimento. Para que isso aconteça, o ensino precisa estar comprometido politicamente com o processo da aprendizagem de todos.

Assim, da mesma forma que não há neutralidade no ato educativo, não há possibilidade de se conceber que uma pessoa com deficiência esteja inserida na escola apenas como forma de possibilitar sua socialização. Essa defesa de que o objetivo da inclusão escolar é a socialização da pessoa com deficiência é profundamente comprometida com uma determinada concepção de homem, de sociedade e de escola, voltada para a reprodução e manutenção da ideologia excludente e dominante. Na concepção durkheimiana, a socialização "compõe o processo de aprendizagem social que permite a absorção das formas de viver da sociedade, seja pensamentos, atitudes, símbolos ou regras" (ATISANO, 2006, p. 33).

Porém, não é essa inclusão, que propõe a mera absorção de atitudes e regras, que se defende neste trabalho como direito de todos, pois a escola é entendida como um espaço de formação do cidadão e de socialização de conhecimentos historicamente construídos, conhecimentos esses necessários para o exercício da cidadania e para o empoderamento e autonomia do cidadão diante da sociedade. Assim, a escola é também o locus para que emanem discussões, transformações e criação de novas regras.

Ao se pensar a escola como um espaço onde emergem as contradições sociais e, sobretudo, onde se encontram todas as formas de diferenças, é preciso também conceber esse espaço como locus gestacional de uma transformação social. É necessário, no entanto, que se compreenda que a escola não é por si só transformadora, porém são as práticas que nela se constroem cotidianamente que podem contribuir para uma educação libertadora e comprometida com a transformação social.

É, portanto, lastreada pela convicção de que a escola deve estar comprometida com a formação de cidadãos para transformação da sociedade que se propõe este texto, trazendo a discussão da didática a serviço da inclusão de pessoas com deficiência na escola comum. Para alcance deste objetivo, num primeiro momento, será discutida a concepção de inclusão assumida neste artigo e, num segundo momento, serão abordados alguns princípios fundantes para uma didática a serviço da inclusão. 


\section{Sobre que inclusão se está falando?}

Para iniciar a reflexão proposta como objetivo deste texto é necessário esclarecer sobre que proposta de inclusão está sendo discutida. Não se pretende aqui fixar-se na discussão da inclusão do ponto de vista da legislação brasileira, nem da perspectiva das conquistas feitas pelos movimentos das pessoas com deficiência no contexto mundial. Entende-se que esta discussão tem sido muito contemplada nos diversos textos que discutem a inclusão escolar de pessoas com deficiência. Assim, objetiva-se refletir neste item que o paradigma da inclusão perpassa por concepções de natureza ética, política e social e, consequentemente, elucidar as condições que precisam ser oferecidas para que tal inclusão aconteça.

Inicialmente é importante que se compreenda a inclusão como um direito do cidadão em condição de deficiência. Direito de ser, estar, pertencer e agir em todos os espaços da sociedade. A garantia deste direito não é, portanto, de modo algum um favor, uma benesse do Estado, mas um reconhecimento do lugar de pertencimento destes cidadãos.

Nesse contexto, cabe também o esclarecimento de que neste texto a deficiência é entendida não como restrita ao aspecto orgânico, mas como resultado das limitações impostas pelo meio no qual o sujeito está inserido. Conforme Art. $2^{\circ}$ da chamada lei brasileira de inclusão da pessoa com deficiência, Lei 13.146/2015,

Art. $2^{\circ}$. Considera-se pessoa com deficiência aquela que tem impedimento de longo prazo de natureza física, mental, intelectual ou sensorial, o qual, em interação com uma ou mais barreiras, pode obstruir sua participação plena e efetiva na sociedade em igualdade de condições com as demais pessoas. (BRASIL, 2015).

Assim, quanto mais limitante, isto é, cheio de barreiras for esse meio, mais a condição de deficiência será potencializada. Ressalte-se que tais barreiras não estão relacionadas apenas as questões arquitetônicas ou relativas à construção de rampas ao invés de escadas nas escolas, mas, para além das descrições trazidas no Art. $3^{\circ}$ da Lei 13.146/2015 a exemplo das barreiras urbanísticas, nos transportes, na comunicação e informação, atitudinais e tecnológicas (BRASIL, 2015), também se abordam neste texto àquelas barreiras de ordem didática. Desse modo, quanto mais distanciado da vivência dos alunos for o conteúdo trabalhado pela escola, mais barreiras se construirão no processo de aprender.

Por isso entende-se que a inclusão de pessoas com deficiência no contexto da escola comum não se resume à garantia do acesso, mas requer transformações no espaço institucional, na cultura escolar e na práxis pedagógica que se desenvolve nesse contexto. Assim, defende-se 


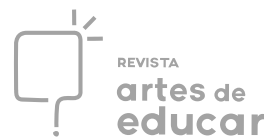

que a inclusão deve promover mudanças na escola tanto no âmbito arquitetônico, quanto no atitudinal e pedagógico para que se efetivem o acolhimento e o trabalho com a diversidade.

As mudanças arquitetônicas, de modo geral, são as mais propaladas quando se aborda a temática da inclusão, pois estão mais visíveis e afetam diretamente o direito de ir e vir, com autonomia e segurança, das pessoas com deficiência. Portanto, necessariamente a inclusão irá requerer modificações na estrutura física das escolas com vistas a que se acolham a todos. Tais mudanças envolverão, dentre outras questões: a construção de rampas; o alargamento das portas das salas; a sinalização através de pistas táteis e do uso do Braille em escrita de sinais para identificação dos espaços; bibliotecas em condição de livre circulação e com livros ao alcance de todos, inclusive dos usuários de cadeira de rodas; sanitários acessíveis; mobiliários adaptados, dentre outros requisitos. Observa-se, então, que o leque das mudanças de ordem arquitetônica depende, precipuamente, de investimentos financeiros para reforma dos prédios escolares já em funcionamento, eliminando as barreiras físicas e comunicacionais, de modo que sejam adequados conforme as normas técnicas da ABNT NBR 9050/2015 ${ }^{1}$, bem como a aquisição de mobiliário ergonomicamente adaptado, de didáticos adaptados e de recursos de Tecnologia Assistiva que possibilitem a funcionalidade e a participação, com autonomia e segurança, de pessoas com deficiência e mobilidade reduzida no espaço escolar.

Porém, por sua vez, as mudanças de ordem atitudinal requerem transformações mais profundas, de natureza cultural, pois exigem o rompimento com a lógica da produtividade que permeia a sociedade capitalista e constitui o imaginário dos sujeitos que dela fazem parte. Essa mudança exige, portanto, o rompimento com atitudes preconceituosas construídas a partir da concepção da deficiência como um castigo, desventura ou problema, que coloca quem vive esta condição numa condição de inferioridade. Nesse sentido, mudar atitudes significa também romper com o receio do convívio com o diferente, com o medo da diferença e com a construção de estigmas e rótulos no interior da escola, pois tais estigmas e rótulos são resultados das construções e percepções sociais que culpabilizam o sujeito, buscando causas individuais e orgânicas para justificar o seu insucesso. É necessário, portanto, romper com a lógica que intensifica a exclusão social e com os argumentos que justificam as desigualdades sociais, problematizando o funcionamento da escola como produtora de desigualdade, fracasso e humilhação. Nesse sentido é necessária também uma mudança no discurso veiculado pelos atores da escola acerca da deficiência. Observa-se, então, que urge essa mudança de ordem

\footnotetext{
${ }^{1}$ Norma revisada em 2015, pela Associação Brasileira de Normas Técnicas (ABNT), que trata da acessibilidade a edificações, mobiliário, espaços e equipamentos urbanos. 
cultural, que exige transformação dos valores e da lógica excludente que têm permeado as ações da sociedade e da escola.

Por fim, a inclusão exige também mudanças de ordem pedagógica de modo que sejam assegurados diferentes ambientes para construção de aprendizagens, através de currículos adaptados que atendam as necessidades concretas de cada estudante. É isso que será abordado no próximo item deste artigo.

Porém, ao finalizar essa discussão sobre inclusão, insta que seja ratificado o alerta de que se as mudanças necessárias à escola não acontecerem, tem-se o risco de criar uma pseudoinclusão e com ela a categoria definida por Bourdieu (2011) como os "excluídos do interior" para os quais a instituição escolar se transforma numa "espécie de terra prometida, sempre igual no horizonte, que recua à medida que nos aproximamos dela". (BOURDIEU, 2011, p. 483).

\section{A didática a serviço da inclusão}

A didática, "como reflexão sistemática e busca de alternativas para os problemas da prática pedagógica" (CANDAU, 2010, p. 13), têm como objeto de estudo os processos que envolvem o ensinar e aprender. Portanto, a didática se compromete com a melhor forma de ensino para que se assegure a aprendizagem. Retoma-se aqui a discussão feita na introdução deste texto de que esse compromisso é, sobretudo, um ato político, rompendo com a concepção de didática que envolve a dimensão meramente técnica, ou seja, o como ensinar.

Portanto, quando o professor se depara com um estudante com deficiência em sua sala de aula ele precisa se comprometer com o seu processo de aprendizagem do mesmo modo que o faz com os demais discentes, reconhecendo que "se fracassarem, (...) estarão destinados a uma exclusão sem dúvida mais estigmatizante e total que no passado: mais estigmatizante na medida em que tiveram, na aparência, 'suas chances"” (BOURDIEU, 2011, p. 483).

A ausência deste compromisso por parte do docente pode promover um tipo de exclusão ou de expulsão oculta, justificada sob o discurso de que foi concedido à pessoa com deficiência o acesso à escola regular, mas o seu fracasso se deu devido a sua incapacidade de nela permanecer. Esta justificativa constitui-se numa representação do que Bourdieu denomina de violência simbólica, isto é, aquela produzida de modo invisível, "não percebida como arbitrária e, portanto, legitimada.” (BUSETTO, 2006, p. 116). Esta prática da violência simbólica é muito presente na cultura escolar que valoriza o capital cultural e o habitus escolar que legitima o êxito 
de uma minoria e, portanto, só será rompida a partir da resistência de professores que se comprometam politicamente com o processo de aprender de todos os seus alunos.

É, então, esse compromisso político com a aprendizagem do outro que deve mobilizar o professor a rever práticas excludentes, que corroboram com uma cultura escolar seletiva, que legitima as desigualdades sociais e a se comprometer com a aprendizagem de todos os seus alunos, mudando sua forma de mediação do ensino diante das dificuldades apresentadas pelo estudante. Se o professor acredita que todos os alunos são capazes de aprender, ele se comprometerá a acompanhar os discentes no desenvolvimento de suas potencialidades. Segundo Vigotski (2001, p. 431),

Por isso duas questões se colocam diante do pedagogo: em primeiro lugar, a do estudo individual de todas as particularidades específicas de cada educando em particular, em segundo, do ajuste individual de todos os procedimentos de educação e interferência do meio social em cada uma delas. Nivelar todas elas é o maior equívoco da pedagogia, e a sua premissa básica requer forçosamente a individualização, requer a definição consciente e precisa dos objetivos individuais da educação para cada aluno.

Há que se ter consciência de que esta afirmação traz inquietação a muitos professores que entendem este acompanhamento personalizado como irreal, diante de turmas com muitos alunos e da ausência de condições de trabalho docente. Conforme já abordado anteriormente, corroborase neste texto com a compreensão de que a inclusão exige mudanças estruturais na escola, dentre as quais deve estar à disponibilização de materiais didáticos adaptados, a redução do número de estudantes nas salas onde há matriculas de discentes com deficiência e a contratação, se necessário for, de profissional de apoio escolar, conforme preconizado pelo inciso XIII, Art. $3^{\circ}$, da Lei 13.146/2015, dentre outras mudanças. Por outro lado, tem-se também que a inclusão prevê, conforme recomendado no parágrafo primeiro do Artigo 58 da Lei de Diretrizes e Bases da Educação Nacional (LDB) no 9.394/96, serviços de apoio especializado na escola regular para atender às peculiaridades dos estudantes com deficiência. (BRASIL, 1996). O Atendimento Educacional Especializado (AEE) é, então, previsto na legislação como forma de complementar ou suplementar a escolarização, devendo, portanto, se constituir como parte de uma rede de apoio que deve ser estabelecida para adequado atendimento ao estudante com deficiência, sendo que o profissional que atua no AEE deve trabalhar colaborativamente com o professor da sala comum, buscando condições de ensino que favoreçam o processo de aprendizagem a todos os discentes.

Assim, defende-se neste trabalho que o estudante com deficiência matriculado na escola comum não se constitui responsabilidade apenas do professor que trabalha diretamente com ele, 


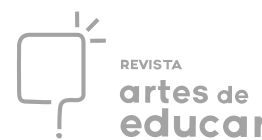

mas, a partir da sua matrícula, deve ser criada uma rede de apoio, envolvendo atores da escola e fora dela, de modo a assegurar a sua inclusão nos processos de ensinar e de aprender.

Diante do exposto, reafirma-se que a intenção neste artigo não é, de modo algum, responsabilizar apenas o professor pelo sucesso da inclusão, mas reitera-se que a ação pedagógica do docente deve estar subsidiada por uma didática inclusiva, compreendendo que o seu aluno "diferente" tem tanto o direito de ser tratado igual a todos, no sentido de assegurar o seu direito a aprender e não apenas a se socializar, quanto, em alguns momentos, ser tratado de modo diferenciado afim de que suas peculiaridades sejam atendidas. Conforme afirma Santos, (2003, p. 56)

Temos o direito a ser iguais quando a nossa diferença nos inferioriza; e temos o direito a ser diferentes quando a nossa igualdade nos descaracteriza. Daí a necessidade de uma igualdade que reconheça as diferenças e de uma diferença que não produza, alimente ou reproduza as desigualdades.

Essa chamada didática da inclusão está, então, amparada em princípios que sustentam o reconhecimento da heterogeneidade das turmas e de que os estudantes são ativos no processo de aprender. Reconhecer a não homogeneidade nas turmas implica também em compreender que há formas diferentes de aprender, portanto uma mesma metodologia e os mesmos recursos didáticos não atendem a necessidade de todos os discentes. O professor precisa, então, estar atento, pois uma pessoa com deficiência visual/baixa visão em sua sala de aula precisará, dentre outras coisas, de materiais didáticos impressos com caracteres ampliados. Por sua vez, o estudante com deficiência visual/cegueira necessitará de textos impressos em Braille ou da disponibilização de textos em formato digital para que utilize software ledores de tela ressalte-se que, nesses casos, não funcionam textos em forma de imagem. Ademais tal estudante também necessitará de que lhe sejam fornecidos recursos didáticos tridimensionais ou em alto relevo de modo a favorecer a construção de uma imagem mental sobre um determinado conteúdo trabalhado. Observa-se, pois, que dentro da própria deficiência visual há necessidades diferenciadas que precisam ser compreendidas e atendidas na escola de modo também diferenciado. Assim, nessa perspectiva entende-se que tratar igualmente aqueles que necessitam de tratamento diferenciado, é estar a serviço da promoção de desigualdades e exclusões.

Por sua vez, numa didática inclusiva, é necessário que o professor compreenda que o processo do ensino deve ser centrado na interação do discente com o conhecimento, devendo ser superadas as práticas focadas no reprodutivismo dos conteúdos conceituais que expõem os discentes à passividade. $\mathrm{O}$ estudante deve, então, ser visto como sujeito ativo, que interage com o meio (físico e social) e constrói seu conhecimento de forma mediada. 
Ao reconhecer esses princípios, anteriormente descritos, o professor revela-se politicamente comprometido com a formação de uma sociedade plural e de um estudante que poderá participar como cidadão nessa sociedade. Nesse sentido, o professor imbuído dessa compreensão desenvolve sua prática observando os seguintes aspectos: 1. o planejamento da mediação pedagógica com base nas necessidades reais dos aprendentes; 2. a necessidade de adaptação do currículo escolar; 3. a importância do estímulo à colaboração entre pares de estudantes; e 4. a necessidade de elaboração de atividades diversificadas.

No primeiro aspecto, ao reconhecer a heterogeneidade dos estudantes o professor compreende a necessidade de planejar, intencionalmente, a mediação pedagógica com base nas necessidades reais dos diferentes aprendentes existentes na sala de aula. Isso representa a criação de condições necessárias para todos, de modo que a aprendizagem lhes seja assegurada.

A proposta de mediação pedagógica é fundamentada na compreensão de que todos têm potencial para aprender, devido à plasticidade cerebral, isto é, a capacidade do cérebro se adaptar as condições que lhe são possibilitadas a partir do reconhecimento das suas potencialidades e necessidades.

É, pois, com base nesse entendimento que o professor vai, intencionalmente, criar condições de ensino ajustadas ao percurso do estudante na construção do conhecimento, podendo tais condições ser modificadas, gradualmente, a depender das necessidades apresentadas pelo estudante no decorrer desse percurso. Nesses casos, uma relevante estratégia a se utilizar é manter constantemente o diálogo com o educando com deficiência, de modo a perceber e aprender com ele quais as maneiras e recursos que potencializam a sua aprendizagem.

Conforme visto, no desenvolvimento da mediação pedagógica o professor atua considerando as necessidades dos estudantes. Assim, torna-se imprescindível que se promova o segundo aspecto citado, ou seja, a adaptação do currículo escolar. Essa adaptação consiste na flexibilização e/ou adequação da proposta curricular e da práxis pedagógica, colocando-a a serviço do direito de todos à aprendizagem. Nesse sentido, o professor poderá, em alguns momentos, modificar, suprimir ou acrescentar objetivos, conteúdos, metodologias e/ou recursos didáticos, objetivando envolver a todos na construção do conhecimento. É possível exemplificar a adaptação curricular quando numa sala com estudantes surdos e ouvintes o objetivo planejado envolve: "Ler com fluência utilizando os sinais de pontuação". Necessariamente, nesse caso, esse objetivo precisará ser modificado, tendo em vista a peculiaridade do estudante surdo que tem, de modo garantido pelo Decreto 5.626/2005, a língua portuguesa como segunda língua na modalidade escrita, sem que lhe deva ser cobrada a oralização. Assim, flexibilizar/adaptar o 
currículo torna-se condição necessária para uma pedagogia que respeite as diferenças dos estudantes no processo de aprendizagem.

Ainda numa didática inclusiva e como uma forma de mediação pedagógica, tem-se como relevante o terceiro aspecto citado: o estímulo à colaboração entre pares de estudantes. Essa é uma prática fundamental para a efetivação da inclusão, pois favorece o fenômeno da chamada aprendizagem colaborativa onde um discente mais experiente co-labora com a aprendizagem do colega, ou seja, trabalha com ele, participando de seu processo de aprendizagem.

Nessa perspectiva, considera-se fundamental que numa sala inclusiva se incentive o trabalho em pequenos grupos. Essa prática reflete o entendimento de que a aprendizagem acontece não apenas através das interações com o professor, mas que os estudantes também interagem e aprendem entre si. Ressalta-se, porém, que esses pequenos grupos devem ser organizados de modo intencional e heterogêneo, ou seja, de forma que um estudante mais experiente colabore com a aprendizagem de seu colega.

Esse princípio se encontra fundamentado na concepção vigotskiana de que a intervenção na chamada zona de desenvolvimento proximal pode ser feita por sujeitos mais experientes da cultura, ou seja, aqueles que já alcançaram aquilo que o outro ainda não alcançou. (VYGOTSKY, 1998). “A zona do desenvolvimento imediato pode determinar para nós o amanhã da criança, o estado dinâmico do seu desenvolvimento que leva em conta não só o já atingido mas também o que se encontra em processo de amadurecimento." (VIGOTSKI, 2001, p. 480).

Para isso é importante que o professor considere, na constituição dos pequenos grupos, a disponibilidade do estudante de cooperar com o colega, no sentido de ajudá-lo a fazer, ou seja, fazer com ele e não de fazer por ele. Dessa forma, constitui-se parte do estímulo à colaboração entre pares que o professor observe as interações produzidas no âmbito dos pequenos grupos, observando se os estudantes estão agindo colaborativamente. Caso essa disponibilidade ainda não esteja consolidada como característica da criança colocada para atuar como um colaborador, uma alternativa viável é a refacção dos grupos até que se alcance o objetivo pretendido.

Uma das formas de abarcar todos os aprendentes no processo de aprendizagem diz respeito ao último aspecto considerado: a elaboração de atividades didáticas diversificadas, isto é, que envolvam um maior número de sentidos (visão, tato, audição etc.). Isso significa ampliar o escopo das aulas meramente expositivas, centradas unicamente na audição e na visão. Não que tais aulas devam ser abolidas, porém é importante diversificar os métodos de ensino, principalmente na faixa etária que abrange o ensino fundamental. Entende-se que nessa faixa 
etária essa diversificação na forma de abordagem de conteúdos é condição precípua para que o estudante sinta-se imerso na proposta da construção de conhecimento.

Desse modo, a proposição de aulas práticas, com experimentos, atividades em campo, vivências de situações concretas (como compras em um mercado), ou uso de filmes e documentários certamente possibilitará o maior envolvimento de toda a turma com o conteúdo trabalhado. Essas formas de abordagem pedagógica, sem dúvida, potencializarão a aprendizagem de todos os estudantes e não apenas dos que vivem a condição de deficiência.

Observa-se, diante do exposto, que as práticas pedagógicas abordadas como necessárias à construção de uma didática inclusiva estão intrinsecamente relacionadas e são amparadas teoricamente no conceito vigotskiano de zona de desenvolvimento proximal, isto é, na criação de condições, através da interação social (professor-aprendente ou aprendente-aprendente), para que sejam fornecidas ajudas ou apoios aos estudantes que vivenciam barreiras ou deficiências no processo de aprendizagem, de modo que possam, ao se apropriar desta ajuda, resolver sozinhos o que só conseguiam resolver com ajuda externa (VYGOTSKY, 1998).

Porém, a partir do reconhecimento da heterogeneidade dos aprendentes, é preciso também que se reconheça que as zonas de desenvolvimento proximal são diversas numa classe, requerendo do professor o planejamento de atividades que sejam desafiadoras para cada estudante, como forma de atender à diversidade sem se descuidar das individualidades. Isso não significa uma atividade diferente para cada estudante, mas a proposição de uma mesma atividade com níveis diferentes de dificuldades, considerando-se as especificidades de cada grupo de estudantes.

Em seu trabalho mediador o professor precisa também considerar que há tempos diferentes para que o discente se aproprie da ajuda ou apoio fornecido. Alguns discentes precisarão de mais tempo de mediação pedagógica ou cooperação de seus pares para se apropriar da ajuda fornecida e esse tempo precisa ser considerado na organização e na adaptação do currículo escolar de modo a atender a diversidade. Nesse sentido, “(...) quanto mais difícil for para a criança a obtenção de um objetivo, mais diretiva deverá ser a intervenção (...)" (WOOD, 1980 apud COLL, 1994, p.140).

Também é necessário observar que se o conteúdo proposto está muito distante - além ou aquém - em relação ao desenvolvimento real do estudante, o mesmo não consegue se mobilizar para aprender e o resultado produzido pode ser a desmotivação. Assim, o professor precisa estar atento com relação ao que o seu aluno já sabe (desenvolvimento real), de modo que o novo conteúdo possa se ancorar nos conceitos pré-existentes na estrutura cognitiva do aprendente, possibilitando, assim, uma aprendizagem significativa (MOREIRA; MASINI, 2006). 
Essa didática que está a serviço da aprendizagem de todos os alunos é, portanto, a que está a serviço da inclusão, retirando do meio do caminho, numa perspectiva drumondiana ${ }^{2}$, as pedras (barreiras) que impedem a aprendizagem dos estudantes com deficiência. Para que isso aconteça o professor precisa problematizar e refletir sobre sua metodologia de ensino e construir formas alternativas para possibilitar condições de aprendizagem para todos.

\section{Considerações finais}

Ao longo deste artigo defende-se a construção de uma didática que esteja a serviço da inclusão e da transformação das práticas de ensinar, de modo que favoreça a aprendizagem de todos os estudantes na escola.

Observa-se, no decorrer do texto, que a prática proposta para uma atuação pedagógica numa perspectiva inclusiva favorece não apenas a aprendizagem das pessoas com deficiência, mas possibilita melhores chances de aprendizagem para todos os discentes. Nesse sentido, compreende-se que a inclusão ratifica as possibilidades de que se assegure a qualidade da educação para todos, ou seja, “(...) a inclusão é boa não só para os "incluídos”, mas, sim, para toda a comunidade que participa e vivencia o processo" (REGIANI; MOL, 2013, p. 132).

A chamada didática inclusiva, proposta neste texto, é, portanto, considerada um ato político, pois é comprometida com a emancipação e autonomia dos estudantes no seu processo de aprendizagem, inclusive daqueles que estão em condição de deficiência. Deste modo, essa didática é também comprometida com a transformação da escola e da sociedade, garantindo a diferenciação de metodologias e recursos para igualar os direitos, principalmente o direito a aprender.

\section{Referências}

ATISANO, Regiane Aparecida. A educação sob o enfoque de Émile Durkheim. In: CARVALHO, Alonso Bezerra de; SILVA, Wilton Carlos Lima da. (Orgs.). Sociologia e Educação: leituras e interpretações. São Paulo: Avercamp, 2006. p. 27-37.

BOURDIEU, Pierre (Coord.). A miséria do mundo, Petrópolis, RJ: Ed. Vozes, 2011.

BRASIL, Lei $n^{o}$ 13.146, de 6 de julho de 2015. Institui a Lei Brasileira de Inclusão da Pessoa com Deficiência (Estatuto da Pessoa com Deficiência).In: Diário Oficial da União, Brasília, DF, 7 de julho de 2015. Disponível em: <http://www.planalto.gov.br/ccivil_03/_ato20152018/2015/lei/113146.htm>. Acesso em: 3 jul. 2017.

\footnotetext{
${ }^{2}$ Referência ao poema de Carlos Drumond de Andrade "No meio do Caminho". 
BRASIL. Lei $n^{\circ} 9.394$ de 20 de dezembro de 1996. Estabelece as Diretrizes e Bases da Educação Nacional In: Diário Oficial da União, Brasília, DF, 23 de dezembro de 1996.

Disponível em: < http://www.planalto.gov.br/ccivil_03/leis/L9394.htm>. Acesso em: 4 jul. 2017.

BRASIL, Constituição da República Federativa do Brasil, Brasília, DF, 1988. Disponível em: <http://www.planalto.gov.br/ccivil_03/constituicao/constituicao.htm>. Acesso em: 28 jun. 2017.

BUSETTO, Áureo. A Sociologia de Pierre Bourdieu e sua análise sobre a escola. In:

CARVALHO, Alonso Bezerra de; SILVA, Wilton Carlos Lima da. (Orgs.). Sociologia e Educação: leituras e interpretações. São Paulo: Avercamp, 2006. p. 113-133.

COLL SALVADOR, César. Aprendizagem escolar e construção do conhecimento. Porto Alegre: Artes Médicas, 1994.

MOREIRA, Marco Antonio; MASINI, Elcie Aparecida S. Aprendizagem significativa: a teoria de aprendizagem de David Ausubel. 2 ed. São Paulo: Centauro Editora, 2006.

REGIANI, Anelise Maria; MOL, Gerson de Souza.Inclusão de uma aluna cega em um curso de licenciatura em Química. Ciência \& Educação (Bauru). [online]. 2013, vol.19, n.1, pp.123-134. Disponível em: http://www.scielo.br/scielo.php?script=sci_arttext\&pid=S1516$\underline{73132013000100009}$ Acesso em: 4 jul. 2017.

SANTOS, Janete dos. Acesso à educação superior: a utilização do ENEM/SISU na Universidade Federal do Recôncavo da Bahia. (Dissertação) Mestrado em Educação. UFBA: Salvador, BA, 2013. Disponível em:

<https://repositorio.ufba.br/ri/bitstream/ri/15231/1/Janete\%20dos\%20Santos_disserta\%C3\%A7 \%C3\%A3o.pdf> Acesso em: 4 jul.2017.

SANTOS, B. de S. Reconhecer para libertar: os caminhos do cosmopolitanismo multicultural. Rio de Janeiro: Civilização Brasileira, 2003.

VIGOTSKI, L. S. Psicologia pedagógica. Martins Fontes: São Paulo- SP, 2001.

VYGOTSKY, L. S. Formação social da mente: o desenvolvimento dos processos psicológicos superiores. São Paulo: Martins Fontes, 1998.

${ }^{\text {i} P r o f e s s o r a ~ A s s o c a i d a ~ d a ~ U n i v e r s i d a d e ~ F e d e r a l ~ d o ~ R e c o ̂ n c a v o ~ d a ~ B a h i a ~(U F R B), ~ a t u a n d o ~ n o ~}$ Programa de Pos-graduação em Gestão de Politicas Publicas e Segurança Social. Também atua no Programa de Pós-graduação em Educação da Universidade Federal da Bahia. 